\title{
Analisis Faktor Kepuasan Konsumen Membeli BBM Pertamax Dan Pertalite Pada SPBU Lanji Kendal
}

\author{
Rido Anggara ${ }^{1}$, Supajar ${ }^{2}$, Juanda ${ }^{3}$, Nur Lutfiyana ${ }^{4}$
}

\begin{abstract}
Transportation activities are currently growing rapidly, both private transportation, mass transportation and distribution operations, all of which cannot be separated from the use of fuel oil (BBM) which is used as the main fuel component in driving in Indonesia. This affects the increase in sales of BBM (fuel oil) which has become a primary need in supporting the activities carried out. So in this study the aim is to determine the factors of consumer satisfaction in choosing fuel oil (BBM) in their vehicle at the Lanji Kendal gas station. At the stage of taking a sample, this research was carried out by direct observation or observation and filling out data/questionnaires for Lanji Kendal gas station customers. So that in the process of filling in the data/questionnaire it can show a result of a facility, service, economic factor and others so that it can determine consumer satisfaction in choosing fuel oil (BBM) at the Lanji Kendal gas station so that in this research what is done is a satisfaction factor analysis consumers buy Pertamax and Pertalite fuel at the Lanji Kendal gas station. Alpha value> 15 so that all items are reliable and all tests consistently have strong reliability.
\end{abstract}

\section{Keywords: Consumer Satisfaction System Buying BBM}

Intisari - kegiatan transportasi saat ini sudah berkembang pesat, baik transportasi pribadi, angkutan masal maupun operasional distribusi, semua tidak lepas dari penggunaan bahan bakar minyak (BBM) yang digunakan sebagai komponen bahan bakar utama dalam berkendara di Indonesia. Hal ini mempengaruhi meningkatnya terhadap penjualan BBM (bahan bakar minyak) yang sudah menjadi kebutuhan primer dalam menunjang aktifitas kegiatan yang dilakukan. Sehingga dalam penelitian ini bertujuan untuk mengetahui faktor kepuasan konsumen dalam memilih bahan bakar minyak (BBM) pada suatu kendaraan mereka di SPBU Lanji Kendal. Pada tahap pengambilan suatu semple penelitian ini melakukan dengan cara melihat secara langsung atau observasi dan mengadakan pengisian data/kuesioner terhadap pelanggan SPBU lanji Kendal. Sehingga dalam proses pengisian data/kuesioner dapat menunjukan suatu hasil dari suatu fasilitas, pelayanan, faktor ekonomi dan lain-lainnya sehingga dapat menentukan kepuasan konsumen dalam memilih bahan bakar minyak (BBM) pada SPBU Lanji Kendal sehingga dalam penelitian ini yang dilakukan adalah analisis faktor kepuasan konsumen membeli BBM Pertamax dan Pertalite pada SPBU Lanji Kendal. Nilai alpha>15 sehingga seluruh item reliabel dan seluruh tes secara konsisten memiliki reliabilitas yang kuat.

Kata Kunci: Sistem Kepuasan Konsumen Membeli BBM

1, 2, 3, 4 Jurusan Sistem Informasi, Universitas Nusa Mandiri, Jln Kramat Raya No. 18 Jakarta Pusat 10450 INDONESIA tlp: 08158544 2191; 021-31908575 e-mail: ridho@nusamandiri.ac.id, supajar@nusamandiriac.id, Juanda@nusamandiri.ac.id,

\section{Pendahuluan}

Di era globalisasi sekarang ini banyak menganggap bahwa kendaraan roda dua maupun kendaraan roda empat sudah menjadi kebutuhan pokok atau primer bukan lagi barang mewah maka dari itu bisa dilihat meningkat pesatnya penguna kendaraan pada setiap hari,bulan, bahkan tahun sehingga dapat mempengaruhi kebutuhan konsumsi bahan bakar minyak dikarenakan hal ini bahan bakar merupakan komponen penting dalam kehidupan masyarakat terutama untuk kendaraan mereka yang mereka gunakan dalam kehidupan sehari hari.

Saat ini jenis bahan bakar minyak sudah sangat beragam di pasaran, dari premium, Bio Solar, Pertamax, Pertalite, Pertamina Dex, Seiring dengan tingginya laju pertumbuhan kepemilikan kendaraan maka secara otomatis tingkat konsumsi dari bahan bakar minyak pun semakin meningkat dari tahun ke tahun.

Akibat dari aktivitas pemakaian kendaraan pribadi dan angkutan umum oleh masyarakat sudah semakin meningkat. Hal tersebut dapat menimbulkan pencemaran udara yang berasal dari knalpot dan mesin kendaraan tersebut. Bahan buangan dari kendaraan bermotor ataupun mobil dikenal sebagai sumber utama bahan-bahan polutan. pencemaran udara dari asap kendaraan bisa memicu terjadinya gangguan pernapasan, seperti asma, ISPA, dan kanker paru-paru. Selain itu, pencemaran udara juga bisa berakhir pada berkurangnya kadar oksigen.

Adanya masalah mengenai kerusakan lingkungan ini memotivasi perusahaan-perusahaan yang bijak dan peduli terhadap kondisi lingkungan. Perusahaan tersebut menciptakan suatu produk yang ramah lingkungan yang bertujuan tidak merugikan konsumen maupun lingkungan sekitar dan membantu memperbaiki kelestarian lingkungan.

PT PERTAMINA sebagai perusahaan BUMN yang bertugas mengelola penambangan minyak dan gas bumi di Indonesia menyadari bahwa isu tentang kelestarian lingkungan semakin memburuk, menjadikan perusahaan raksasa tesebut selalu berinovasi dalam mengeluarkan produk - produk bahan bakar minyak yang ramah lingkungan untuk didistribusikan ke SPBU seluruh Indonesia yang bertujuan untuk mengurangi tingkat kerusakan lingkungan.

PT Pertamina melakukan suatu gerakan untuk memaksimalkan penggunaan BBM yang ramah lingkungan, lebih irit dan aman. Produk tersebut yang saat ini menjadi kebanggaan PERTAMINA adalah BBM nonsubsidi Pertamax dan Pertalite.

Kelebihan dari Pertamax adalah Pertamax tidak memiliki kandungan timbal yang berbahaya bagi paru-paru. memiliki angka oktan minimal 92 berstandar Internasional. Angka oktan yang tinggi ini membuat pembakaran menjadi 
lebih sempurna dan tidak meninggalkan residu. Selain menghasilkan pembakaran yang sempurna, Pertamax juga memiliki kelebihan lainnya berkat formula PERTATEC (Pertamina Technology), formula zat aditif yang memiliki kemampuan untuk membersihkan endapan kotoran pada mesin sehingga mesin jadi lebih awet, menjaga mesin dari karat serta pemakaian bahan bakar yang lebih efisien. Serta mampu menjaga kemurnian bahan bakar dari campuran air sehingga pembakaran menjadi lebih sempurna (demulsifier). Pertamax merupakan BBM sehari-hari yang memberikan performa dengan perlindungan mesin terbaik.

Pertalite pertama kali diperkenalkan Pertamina di Indonesia pada 2015 lalu. Bahan bakar tersebut sebenarnya diluncurkan sebagai alternatif peralihan dari Premium, sehingga penggunaan Pertalite lebih disarankan dibandingkan Premium. Pertalite memiliki kadar RON (Research Oktan Number) yang lebih tinggi dengan angka 90, dibanding dengan Premium yang memiliki RON 88. Angka oktan yang lebih tinggi pada Pertalite ini menandakan kualitas bahan bakar yang ramah lingkungan karena pembakaran yang sempurna dan efisien, sehingga lebih tepat digunakan untuk kendaraan jalanan Indonesia. Jika dibandingkan dengan BBM Pertamax, Pertalite menawarkan harga yang lebih murah sebagai BBM ramah lingkungan dengan nilai oktan tinggi serta rendah emisi. Selain itu, hasil bahan bakar Pertalite diklaim lebih optimal dengan diberikan tambahan bahan additive, sehingga kendaraan yang menggunakan Pertalite dapat menempuh jalan yang jaraknya jauh, namun kualitasnya tetap terjaga.

\section{Metode PENELITIAN}

Dalam metode penelitian ini kami melakukan beberapa cara pengumpulkan data dan hasil penelitian untuk menjadi bahan pembahasan skripsi yang kami ajukan. Adapun metode yang kami gunakan dalam menunjang penyusunan skripsi ini sebagai berikut :

\section{A. Observasi}

Observasi merupakan salah satu metode pengumpulan data dengan cara mengamati atau meninjau secara cermat dan langsung di lokasi penelitian untuk mengetahui kondisi yang terjadi atau membuktikan kebenaran dari sebuah desain penelitian yang sedang dilakukan. Kegiatan observas: 1. dilakukan untuk memproses objek dengan maksud untuk merasakan dan kemudian memahami pengetahuan dari sebuah fenomena berdasarkan pengetahuan dan ide-ide yang sudah diketahui sebelumnya, untuk mendapatkan informasi yang diperlukan dan melanjutkan ke proses investigasi.

\section{a. Tahap Persiapan}

Merupakan tahap penyusunan rencana observasi. Hendaknya mempunyai pemahaman tentang latar belakang tujuan dilakukannya pengamatan tersebut serta memahami kebutuhan dalam tahapan persiapan observasi.

b. Tahap Pelaksanaan
Langkah-langkah yang dilakukan dalam pelasanaan observasi. Hendaknya kita memahami tahapan pelaksanaan observasi. Agar data yg dikumpulkan sesui dengan harapan pengumpulan data.

c. Tahap penyusunan Observasi

Hasil observasi merupakan bahan untuk membuat laporan, disusun berdasarkan format yang telah ditentukan.

\section{B. Kuesioner}

Kuisioner merupakan teknik dalam pengumpulan data yang dilakukan dengan cara memberikan pertanyaan secara tertulis kepada responden untuk dijawab dengan memberikan poin sesuai dengan pilihan yang tersedia. Kuisioner merupakan salah satu teknik pengumpulan data yang efisien jika mengetahui dengan pasti variabel yang diukur dan mengetahui apa yang diharapkan dari responden. Kuisioner juga dilakukan apabila responden yang cukup banyak dan tersebar di beberapa wilayah yang luas. Penggunaan kuisioner ini digunakan sebagai alat ukur, sehingga tercipta suatu kondisi yang cukup baik karena menghasilkan data yang obyektif dan cepat.

\section{Wawancara}

Wawancara adalah tanya jawab antara dua pihak secara langsung yaitu antara pewawancara dan narasumber untuk memperoleh suatu data atau pendapat tentang suatu hal.

1) Jenis-jenis wawancara

1. Wawancara Serta Merta

Wawancara serta merta adalah wawancara yang dilakukan dalam situasi alamiah.

2. Wawancara dengan Petunjuk Umum

Wawancara dengan Petunjuk Umum adalah wawancara dengan berpedoman dengan petunjuk-petunjuk pada pokok-pokok yang akan dibahas suatu permasalahan.

3. Wawancara pada Pernyataan

Wawancara pada pernyataan adalah sesuatu kegiatan yang sudah dilakukan dalam pewawancara mengajukan pernyataan berdasarkan daftar pertanyaan yang telah dibuat.

2) Tahap-Tahap Wawancara

1. Tahapan persiapan

Merupakan suatu kegiatan yang dimana menentukan maksud dan tujuan pada topik yang di wawancarakan.

2. Tahapan Pelaksanaan

Merupakan suatu Tahapan awal pada suatu kegiatan wawancara kepada narasumber untuk memperkenalkan diri dan mengutarakan maksud dan tujuan pada pokok-pokok yang diwawancarakan.

3. Tahapan Penyusunan Hasil

Merupakan tujuan dan ringkasan isi wawancara yang telah dilaksanakan dapat di tulis dalam bentuk dialog dalam suatu narasi. 


\section{TAHAPAN PENELITIAN}

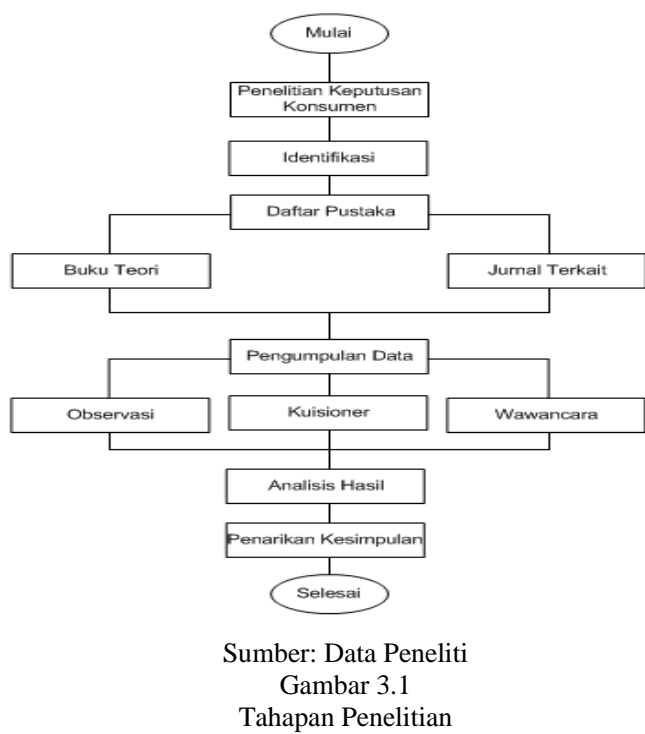

IV. ANGGARAN BIAYA

Tabel 4.1

Anggaran Biaya

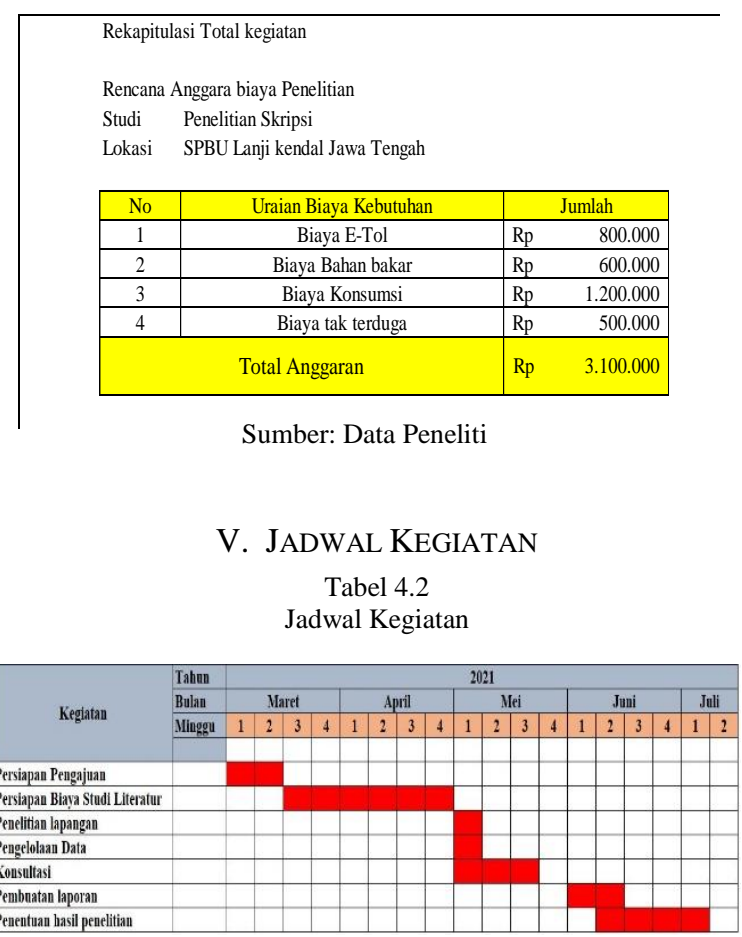

Sumber: Data Peneliti

\section{HASIL DAN PEMBaHASAN}

Dalam hal ini pembahasan tentang analisis pelayanan kepada konsumen sekaligus menerangkan secara garis besar Pemilihan kebutuhan konsumen dalam menggunakan bahan bakar minyak serta perhitungan beberapa metode yang digunakan untuk menentukan hasil.

\section{A. Pelayanan}

Menurut Kotler (2008) pelayanan adalah setiap tindakan atau kegiatan yang dapat ditawarkan oleh suatu pihak kepada pihak lain, yang pada dasarnya tidak berwujud dan tidak mengakibatkan kepemilikan apapun. Menurut Moenir (2008) pelayanan adalah serangkaian kegiatan yang berlangsung secara rutin dan berkesinambungan meliputi seluruh kehidupan orang dalam masyarakat.

Selanjutnya Sinambela (2008) mengemukakan bahwa pelayanan adalah setiap kegiatan yang menguntungkan dalam suatu kumpulan atau kesatuan, dan menawarkan kepuasan meskipun hasilnya tidak terikat pada suatu produk secara fisik. Hal ini menunjukan bahwa pelayanan berkaitan dengan kepuasan batin dari penerima pelayanan.

Pengertian pelayanan menurut Zein (2009) adalah sebuah kata yang bagi penyedia jasa merupakan sesuatu yang harus dikerjakan dengan baik. Sedangkan definisi pelayanan menurut Mahmoedin (2010) adalah suatu aktivitas atau serangkaian aktivitas yang bersifat tidak kasat mata yang terjadi sebagai akibat adanya interaksi antara konsumen dengan karyawan atau hal - hal lain yang disediakan oleh perusahaan pemberi pelayanan yang dimaksud untuk memecahkan permasalahan konsumen/pelanggan.

\section{B. Analisis Data}

Analisis data adalah proses pengolahan data dengan tujuan untuk menemukan informasi yang berguna yang dapat dijadikan dasar dalam pengambilan keputusan untuk solusi suatu permasalahan. Proses analisis ini meliputi kegiatan pengelompokkan data berdasarkan karakteristiknya, melakukan pembersihan data, mentransformasi data, membuat model data untuk menemukan informasi penting dari data tersebut.

\section{a. Karakteristik Responden}

Responden yang digunakan dalam penelitian ini yaitu responden yang ditemui di SPBU Lanji Kendal. Dengan hasil penyebaran kuisioner terhadap 50 responden sehingga didapatkan karakteristik responden berdasarkan jenis kelamin, usia, Penghasilan, Pekerjaan. Sehingga paparan hasil dapat diketahui:

1). Karakteristik Jenis Kelamin Berdasarkan penelitian yang diperoleh karakteristik responden ialah pada jenis kelamin disajikan pada 2 table berikut ini: 
Karakteristik Responden

\begin{tabular}{|l|c|c|}
\hline \multicolumn{1}{|c|}{ Jenis Kelamin } & Frekuensi & Prosentase \\
\hline Laki-laki & 35 & $70 \%$ \\
\hline Perempuan & 15 & $30 \%$ \\
\hline Total & 50 & 50 \\
\hline
\end{tabular}

Tabel ini menjelaskan mayoritas pembelian suatu bahan bakar minyak ataupun penggunaan kendaraan ialah pada laki-laki dibandingkan perempuan sehingga responden pembelian dominan pada laki-laki dengan $70 \%$ dan perempuan sebanyak $30 \%$ dapat disimpulkan mayoritas pembelian pada SPBU Lanji Kendal ialah laki-laki.

\section{2). Karakteristik Usia}

Karakteristik responden berdasarkan usia diperlukan sebab untuk mengetahui konsumen yang datang di SPBU LANJI KENDAL berasal dari kalangan apa saja. Apakah anak muda, dewasa, atau sampai dengan orang tua karakteristik usia disajikan pada 3 table sebagai berikut;

Tabel 4.4

Karakteristik Usia

\begin{tabular}{|l|c|c|}
\hline \multicolumn{1}{|c|}{ Penghasilan } & Frekuensi & Prosentase \\
\hline$<2.000 .000$ & 15 & $30 \%$ \\
\hline $2.000 .000-3.500 .000$ & 23 & $46 \%$ \\
\hline$>3.500 .000$ & 12 & $24 \%$ \\
\hline Total & 50 & $100 \%$ \\
\hline
\end{tabular}

Sumber; Data Peneliti

Berdasarkan hasil data table yang disajikan usia responden paling banyak ialah diangka sekitar 25-40 tahun dalam pembelian BBM yaitu $50 \%$ dan dibawah 25 tahun dapat $40 \%$ diatas 40 tahun adalah $10 \%$ sehingga SPBU Lanji Kendal pembelinya adalah mayoritas seorang dewasa.

Tabel 4.5

Karakteristik Usia

\begin{tabular}{|l|c|c|}
\hline \multicolumn{1}{|c|}{ Usia } & Frekuensi & Prosentase \\
\hline$<25$ tahun & 20 & $40 \%$ \\
\hline $25-40$ tahun & 25 & $50 \%$ \\
\hline$>40$ tahun & 5 & $10 \%$ \\
\hline Total & 50 & $50 \%$ \\
\hline
\end{tabular}

3). Karakteristik Penghasilan

Data karakterisitk ini bertujuan untuk mengetahui penghasilan seorang responden saat melakukan pembelian BBM pada SPBU Lanji Kendal sehingga dapat menyimpulkan kalangan menengah ke bawah, Menengah, dan atas.

Tabel 4.6

Karakteristik Penghasilan

\begin{tabular}{|l|c|c|}
\hline \multicolumn{1}{|c|}{ Penghasilan } & Frekuensi & Prosentase \\
\hline$<2.000 .000$ & 15 & $30 \%$ \\
\hline $2.000 .000-3.500 .000$ & 23 & $46 \%$ \\
\hline$>3.500 .000$ & 12 & $24 \%$ \\
\hline Total & 50 & $100 \%$ \\
\hline
\end{tabular}

Sumber: Data Peneliti

Dalam data responden ini ialah dimana mayoritas penghasilan seorang konsumen pada SPBU Lanji Kendal ialah 2.000.000 - 3.500.000 yaitu 46\% dan <2.000.000 ialah $30 \%$ lalu diatas > 3.500 .000 mendapatkan $24 \%$ dapat disimpulkan penghasilan pembelian pada SPBU Lanji Kendal ialah dengan penghasilan 2.000.000 - 3.500.000.

\section{4). Karakterisitik Pekerjaan}

Karakteristik Responden selanjutnya adalah berdasarkan pekerjaan. Data ini diperlukan untuk mengetahui berasal dari kalangan mana suatu konsumen dalam membeli BBM Pada SPBU Lanji Kendal.

Tabel 4.7

Karakteristik Pekerjaan

\begin{tabular}{|l|c|c|}
\hline \multicolumn{1}{|c|}{ Pekerjaan } & Frekuensi & Prosentase \\
\hline PNS & 10 & $20 \%$ \\
\hline Pegawai swasta & 20 & $40 \%$ \\
\hline Pedagang & 15 & $30 \%$ \\
\hline Mahasiswa & 5 & $10 \%$ \\
\hline Total & 50 & $100 \%$ \\
\hline
\end{tabular}

Sumber: Data Peneliti

Berdasarkan hasil pada table pekerjaan responden paling banyak ialah seorang pegawai swasta yang dimana mereka bekerja pada pagi hari dan dinomer 2 ialah pedagang saat melaksanakan pembelian BBM dinomer 3 ada PNS dan nomer 4 ada Mahasiswa dengan presentase kecil yaitu $10 \%$.

\section{b. Uji Reability}

Ghozali (2009) menyatakan bahwa reliabilitas adalah alat untuk mengukur suatu kuesioner yang merupakan indikator dari peubah atau konstruk. Suatu kuesioner 
dikatakan reliabel atau handal jika jawaban seseorang terhadap pernyataan adalah konsisten atau stabil dari waktu ke waktu. Reliabilitas suatu test merujuk pada derajat stabilitas, konsistensi, daya prediksi, dan akurasi. Pengukuran yang memiliki reliabilitas yang tinggi adalah pengukuran yang dapat menghasilkan data yang reliabel.

Pengujian reliabilitas instrumen dengan menggunakan rumus Alpha Cronbach karena instrumen penelitian ini berbentuk angket dan skala bertingkat.

$$
r_{11}=\left(\frac{n}{n-1}\right)\left(1-\frac{\sum \sigma_{t}^{2}}{\sigma_{t}^{2}}\right)
$$

Keterangan :

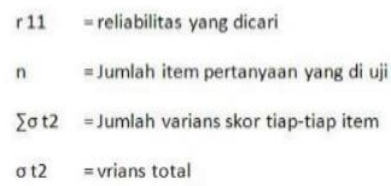

Gambar 4.1

Rumus Alpha

Jika nilai alpha $>0.7$ artinya reliabilitas mencukupi (sufficient reliability) sementara jika alpha $>0.80$ ini mensugestikan seluruh item reliabel dan seluruh tes secara konsisten memiliki reliabilitas yang kuat. Atau, ada pula yang memaknakannya sebagai berikut:

\section{Case Processing Summary}

Tabel 4.8

Case Processing Summary

N

\begin{tabular}{llll}
\hline Cases & Valid & 51 & 100.0 \\
\cline { 2 - 3 } & Excluded $^{\mathrm{a}}$ & 0 & .0 \\
\cline { 2 - 3 } & Total & 51 & 100.0 \\
\hline
\end{tabular}

Sumber: Data Peneliti

Reliability Statistics

Tabel 4.9

Reliability Statistics

\begin{tabular}{|c|l|}
\hline Cronbach's Alpha & N of Items \\
\hline .902 & 15 \\
\hline
\end{tabular}

Sumber:Data peneliti

\section{KESIMPULAN}

Maka dari hasil penelitian dan Pembahasan yang telah diuraikan sebelumnya sehingga dapat ditarik sebuah kesimpulan .

1. Hasil dari analisis menunjukan kepuasan konsumen dalam segi pelayanan dapat dilihat dari hasil pengisian kuesioner atau nilai dari kuesioner sehingga dapat dilihat seberapa baiknya dalam segi pelayanan.

2. Tingkat hasil kepuasan konsumen beserta tanggapan konsumen dalam Kepuasan pelayanan pembelian SPBU Lanji Kendal dapat diketahui dengan hasil Uji Reability sehingga Data lebih akurat untuk mengetahui Kepuasan Konsumen.

3. Tingkat Geografi Konsumen dapat kita ketahui dalam table yang telah diuraikan sehingga dapat mengetahui pendidikan,penghasilan konsumen.

\section{SARAN}

Bagi suatu perusahaan SPBU Kendal Lanji hendaknya perusahaan lebih mendekatkan diri kepada kebutuhan suatu konsumen dan lebih ditingkatkan lagi dalam pelayanan yaitu;

Dengan menyediakan Keperluan konsumen yang memiliki suatu kendaraan yaitu seperti jasa Penggati Oli dan Pengisian Angin ban Dan menawarkan Produk lain seperti menawarkan Pelumas kendaraan bermotor dan mobil kepada konsumen.

\section{REFERENSI}

[1] Ratna Ekasari, W. P. (2018). PENGARUH IKLAN, KUALITAS PELAYANAN, FASILITAS TERHADAP KEPUTUSAN KONSUMEN DALAM PEMBELIAN BBM DI SPBU COCO 51.601.108 MASTRIP SURABAYA. Volume 1, No. 2 Tahun 2018, 13.

[2] Suryawardana, E., \& Yani, T. E. (2017). Analisis Pengaruh Reputasi, Kualitas Pelayanan dan Kepercayaan Terhadap Keputusan Pembelian pada Stasiun Pengisian Bahan Bakar Umum (SPBU) di Kota Semarang. Jurnal Dinamika Sosial Budaya, 17(2), 258-269.

[3] Gumiar, A. M. (2017). Pengaruh Kualitas Pelayanan Terhadap Kepuasan Pelanggan Pada Spbu 34-42120 Ciagel Serang.

[4] Fahrian, F., Hasiolan, L. B., \& Haryono, A. T. (2015). Pengaruh Citra Merek, Lokasi, Kepercayaan Dan Kualitas Pelayanan Terhadap Minat Membeli Bbm Di Spbu Gasindo Mekar Putra Semarang. Journal of Management, 1(1).

[5] Kubangun, H., \& Kalidupa, M. (2020). Pengaruh Kualitas Pelayanan SPBU Terhadap Kepuasan Konsumen Di Kabupaten Buru (Studi Pada SPBU Lala):(the Effect of Quality of SPBU Service to Customer Satisfaction in Buru Regency). Uniqbu Journal of Exact Sciences, 1(2), 10-17.

[6] Pamungkas, G., \& Barata, D. D. (2016). Pengaruh kualitas pelayanan terhadap kepuasan pelanggan serta dampaknya terhadap loyalitas pelanggan pada SPBU 34.151. 37. Kalbi Socio, 3(1), 42-48.

[7] Krisnawati, S. N. (2016). Analisis Pengaruh Kualitas Pelayanan Terhadap Kepuasan Pelanggan SPBU No. 64.751. 15 Samarinda. $e$ Journal Administrasi Bisnis.

[8] Anuwar, N. M., Setyariningsih, E., \& Utami, B. (2019). Analisis Pengaruh Dimensi Kualitas Pelayanan Terhadap Kepuasan Pelanggan Di SPBU (STUDI SPBU NO. 54.613. 20 KEMLAGI MOJOKERTO) (Doctoral dissertation, Universitas Islam Majapahit). 
[9] Vidyarana, I. J. (2020). Pengaruh Standar Operasional Prosedur (SOP) terhadap Kualitas Pelayanan di SPBU 44.551. 17 Kota Yogyakarta.

[10] NURHAFIZAH, N. (2019). ANALISIS KUALITAS PELAYANAN SPBU PADA PT. AMIN PERKASA SINTANG (Doctoral dissertation, Fakultas Ekonomi \& Bisnis).

[11] Suprianto, S. (2021). Analisis pengaruh kualitas pelayanan dan fasilitas terhadap kepuasan pelanggan (studi kasus pada SPBU 14.227. 318 PT. Panca Hammar Lestari Panyabungan) (Doctoral dissertation, IAIN Padangsidimpuan).

[12] Umam, H. (2019). Pengaruh Lokasi Dan Kualitas Pelayanan Terhadap Keputusan Pembelian Di Spbu Pertamina (Kutabumi).

[13] Kesuma, A. T. (2018). EVALUASI KUALITAS PELAYANAN BERBASIS SOP STUDI PADA OPERATOR SPBU 34.17121 BEKASI.

[14] Ramadhan, G. (2020). PENGARUH FASILITAS DAN KUALITAS PELAYANAN TERHADAP KEPUASAN PELANGGAN (Studi Pada PT JOEDHOPRAJITNO SPBU 64.701. 02 Kota Banjarmasin) (Doctoral dissertation, Universitas Islam Kalimantan $\mathrm{MAB})$.

[15] POHAN, G. R. U. (2020). PENGARUH KUALITAS PELAYANAN, PERSEPSI HARGA, DAN KEPERCAYAAN TERHADAP LOYALITAS PELANGGAN MELALUI KEPUASAN PELANGGAN SPBU PERTAMINA DI JAKARTA (Doctoral dissertation, Universitas Tarumanagara)

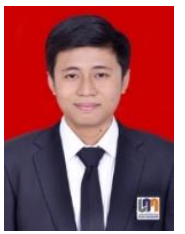

Rido Anggara, Bekasi, 28 Febuari 1999, Lulus D3 Di Universitas Bina Sarana Informatika Pada tahun 2020 dan S1 di Univeristas Nusa Mandiri Pada Tahun 2021, Bekerja Di PT.Suri Nusantara Jaya Sebagai Staff Toko Yang dimana memastikan kebutuhan Setiap hari Dalam Penjualan Perusahaan Tersedia.

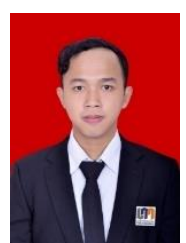

Supajar, Bogor, 18 Mei 1998, Lulus D3 Di Universitas Bina Sarana Informatika Pada tahun 2020 dan S1 di Univeristas Nusa Mandiri Pada Tahun 2021, Bekerja PT. Sicepat Ekspres Indonesia sebagai Supervisor yang dimana bertanggung jawab terhadap laporan masuk dan keluarnya barang.

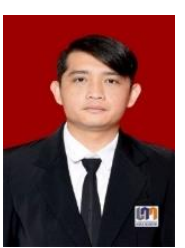

Juanda, Jakarta, 3 April 1987, Lulus D3 Di Universitas Bina Sarana Informatika Pada tahun 2020 dan S1 di Univeristas Nusa Mandiri Pada Tahun 2021, PT. Fast Food Indonesia sebagai Kepala Toko yang bertanggung jawab terhadap omset dan penjualan pada Toko tersebut.

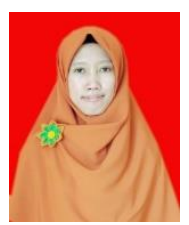

Nur Lutfiyana, M.Kom lahir di Jakarta pada tahun 1987 lulus program strata satu (S1) Jurusan Sistem Informatika STMIK Nusa Mandiri pada tahun 2010. Tahun 2015 lulus program Pasca Sarjana Magister Ilmu Komputer STMIK Nusa Mandiri Jakarta. Saat ini aktif sebagai dosen di Universitas Bina Sarana Informatika dan Universitas Nusa Mandiri Jakarta, aktif menulis dibeberapa buku dan jurnal. 